\title{
Protection of Cyclophosphamide Induced Myelosuppression by Extracts of Asparagus setaceous Kunth and Caesalpinia volkensii Harm in Albino Rats
}

\author{
Kenneth O. Ogila, Oduor M. Aduol*
}

Jomo Kenyatta University of Agriculture and Technology, Department of Zoology, P. O. Box 62,000-00200, Nairobi, Kenya.

*Corresponding author: Oduor M. Aduol, Jomo Kenyatta University of Agriculture and Technology, Department of Zoology, P. O. Box 62,000-00200, Nairobi, Kenya, E-mail: oduormichaela@ gmail.com

Received: March 20, 2017; Revised: July 25, 2017; Published: August 17, 2017

Copyright: @2017 Ogila KO, et al. This is an open-access article distributed under the terms of the Creative Commons Attribution License, which permits unrestricted use, distribution, and reproduction in any medium, provided the original author and source are credited. The article has been previewed and authenticated by the Authors before sending the publication for print. The Journal, Editor and the Editorial Board are not entitled or liable to either justify or responsible for inaccurate and misleading data if any. It is the sole responsibility of the Author concerned.

Citation: Ogila KO, Aduol OM. Protection of Cyclophosphamide Induced Myelosuppression by Extracts of Asparagus setaceous Kunth and Caesalpinia volkensii Harm in Albino Rats. Int J Pharm Pharmacol 2017; 1: 114. doi: 10.31531/2581-3080.1000114

\begin{abstract}
Cancer is a leading cause of disease worldwide. In 2012, there were an estimated 14.1 million new cases of cancer in the world. Chemotherapy has been one of the ways to manage cancers. Unfortunately, chemotherapeutic agents used have been observed to have toxic side effects limiting their use. Accordingly, several new strategies are being developed to control and treat cancer. One such approach could be a combination of an effective phytochemical with chemotherapeutic agents, which when combined would enhance efficacy while reducing toxicity to normal tissues. There is a continued interest and need for the identification and development of nontoxic and effective chemopreventive compound that can reduce the side effects of cyclophosphamide. This study was conducted to establish the protective effects of extracts of Asparagus setaceous Kunth and Caesalpinia volkensii Harm against cyclophosphamide induced myelosuppression in albino rats. In one experimental setup, WBC count was first conducted in all groups of animals. Myelosuppression was then induced by treating animals with single doses of cyclophosphamide and another WBC count done on day 4. The animals were then orally administered with the various extracts and WBC count done on day 9. In another experimental setup, the protective effect of the extracts against cyclophosphamide induced myelosuppression in the experimental rats was assessed. WBC count was first conducted in the groups of animals followed by extract treatments and another WBC count. The animals were then treated with single dose of cyclophosphamide and WBC counts done at various days. The results were analyzed using student t-test. WBC count was found to be significantly reduced following cyclophosphamide treatment. Administration of dichloromethane leave and all ethanolic, methanolic and aqueous extracts were found to reverse leukopenia in albino rats. Hexane extracts did not reverse leukopenia.
\end{abstract}


The extracts were also found to protect the animals against cyclophosphamide induced myelosuppression when animals were first treated with the extracts. These results suggest that the extracts of the two plants are able to reverse myelosuppression induced by cyclophosphamide treatment opening up the possibilities for the use of plant products in the prevention of adverse bone marrow effects associated with cyclophosphamide treatment.

Keywords: Extracts, WBC counts, Cyclophosphamide, Chemopreventive, Myelosuppression, Immunomodulants

\section{Introduction}

Cancer is the third leading cause of death worldwide, preceded by cardiovascular and infectious diseases. It is a generic term for a group of more than 100 diseases that can affect any part of the body [1]. Although there are many therapeutic strategies including chemotherapy to treat cancer, high systemic toxicity and drug resistance limit the successful outcomes in most cases. Most of the synthetic chemotherapeutic agents available today are immunosuppressant, cytotoxic and exert several side effects. Cyclophosphamide is probably the most common antineoplastic used in cancer chemotherapy and is an essential component of several effective chemotherapeutic formulae. It has a broad spectrum of activity against a variety of cancers. However, cyclophosphamide shows potent immunosuppressing properties [2,3] having suppressive and cytotoxic activity. It has a number of side effects in long term treatment. The major side effect of this drug is on immune system and haematological suppression [4,5]. Cyclophosphamide administration induces acute and transient myelosuppression, primarily through damage to rapidly proliferating hematopoietic progenitors and their mature progeny leading to decline in the number of peripheral blood cells [6]. Cytotoxicity towards normal host tissue is the primary dose limiting factor in cyclophosphamide therapy that reduces quality of life and restricts treatment protocol [6]. Accordingly, several new strategies are being developed to control and treat cancer. One such approach could be a combination of an effective phytochemical with chemotherapeutic agents, which when combined would enhance efficacy while reducing toxicity to normal tissues. There is a continued interest and need for the identification and development of nontoxic and effective chemopreventive Ogila KO, et al. Int J Pharm Pharmacol compound that can reduce the side effects of cyclophosphamide. Plants afford us such an opportunity. A number of medicinal plants have attracted the interest of scientists and plant extracts used in traditional therapy are being investigated for their chemopreventive activities [5-7]. Two Kenyan plants namely Asparagus setaceous Kunth and Caesalpinia volkensii Harm are such plants that could be investigated on their chemopreventive activity. Asparagus setaceous belong to the family Liliaceae while Caesalpinia volkensii belongs to Caesalpinacea. Many medicinal uses of the various parts of plants from these two families have been reported in traditional folklore medicines. These have reportedly been used in the treatment of inflammatory diseases, bronchitis, pneumonia, syphilis and other venereal diseases, malaria and anti-helminthic $[8,9]$. The extracts of these two plants have been investigated and demonstrated to possess immunomodulatory activities in experimental animals [10-12]. In current study, we investigated extracts of the two plants for protection in cyclophosphamide induced myelosuppression in albino rats since little is known about the ability of these extracts to reverse cyclophosphamide induced myelosuppression in experimental animals.

\section{Materials and Methods}

\section{Experimental Animals}

Male and female albino rats weighing between 140-210 g used in the study were obtained from the animal house in the Department of Zoology, JKUAT. They were housed five per cage, maintained in an animal house under a 12:12-h light-dark cycle at a temperature of $25^{\circ} \mathrm{C}$ and fed on rat pellet and tap water $a d$ libitum. 


\section{Plant Materials and their Collection}

Plant materials were collected from Gatundu [1 $3^{\circ} 0^{\prime} \mathrm{S}: 36^{\circ} 54^{\circ} 0^{\prime} \mathrm{E}$ ] located in Central province of Kenya during the month of January 2013. Gatundu is approximately $40 \mathrm{~km}$ north of Nairobi. Aerial part and root of Asparagus setaceous and the leaves, stem and root of Caesalpinia volkensii were collected. The plants were identified in the herbarium, Department of Botany JKUAT, where voucher specimens were deposited. The plant materials were dried under shade at temperature below $30^{\circ} \mathrm{C}$ and pulverized in a hammer mill fitted with a sieve of $0.5 \mathrm{~mm}$ pore

\section{Preparation of Plant Extracts}

\section{Preparation of Organic Extracts}

The grounded plant material was extracted twice with organic solvents, hexane, dichloromethane, methanol and $90 \%$ ethanol at room temperature. Hundred grams of plant powder were extracted by mixing with $300 \mathrm{ml}$ of the extracting solvent. The slurry of solvent and plant powder was stirred and left to stand for 48 hours, after which the supernatant was decanted. The decanted supernatants were filtered through Whatman ${ }^{\circledR}$ GF/C glass microfibre filter paper and the filtrate concentrated under vacuum at $40^{\circ} \mathrm{C}$ in Buchii rotary evaporator and dried in a freeze drier. The dry extracts were weighed and kept desiccated at $4^{\circ} \mathrm{C}$ until use.

\section{Preparation of Aqueous Extracts}

Plant powders weighing $300 \mathrm{~g}$ were boiled for twenty minutes in $800 \mathrm{ml}$ of distilled water. After cooling to room temperature, the supernatants were decanted, centrifuged at $5400 \times$ gravity for $10 \mathrm{~min}$ after which the supernatants were filtered through Whatman ${ }^{\circledR}$ $\mathrm{GF} / \mathrm{C}$ glass microfibre filter paper, frozen at $15^{\circ} \mathrm{C}$ and then dried in a freeze-drier. The extracts were weighed and kept desiccated at $4^{\circ} \mathrm{C}$.

\section{Preparation of Extracts for Administration to Rats}

The dichloromethane, hexane, methanol, ethanol and aqueous extracts of $C$. volkensii leaf, stem and root, and A. setaceous aerial part and root were prepared by dissolving in dimethyl sulfoxide. All the plant extracts were dissolved so that the final volume of the solutions did not exceed $1 \mathrm{ml}$.

\section{Experimental Groups}

Rats were divided into 27 groups of 5 individuals each with two groups serving as controls. The groups were categorized as follow: Group 1 to 5 rats treated with dichloromethane extracts of $C$. volkensii leaf, stem and root and A. setaceous aerial part and root respectively and coded as DCVL, DCVS, DCVR, DASA, and DASR. Groups 6 to 10 were treated with methanolic extracts and coded as MCVL, MCVS, MCVR, MASA and MASR while groups 11 to 15 were treated with ethanolic extracts of the two plant parts and coded as follow, ECVL, ECVS, ECVR, EASA and EASR. Groups 18 to 22 were treated with hexane extracts of the two plant parts (HCVL, HCVS, HCVR, HASA and HASR) whereas groups 23 to 27 were treated with aqueous extracts of $C$. volkensii and A. setaceous and coded as ACVL, ACVS, ACVR, AASA and AASR. Group 16 categorized as the dry control was not manipulated in any way while Group 17 which was taken as treated control was administered with the solvent used to dissolve the extracts, dimethyl sulfoxide. All the other remaining groups were treated with the various crude extracts of $C$. volkensii and A. setaceous.

\section{Bleeding of the rats}

Blood was obtained from the tails of the rats. The tails were first sterilized by swabbing with $70 \%$ ethanol and then the tip of the tails snipped with sterile scissors. Bleeding was enhanced by gently "milking" the tail from the body towards the tip. After the operation, the tip was sterilized again by swabbing with $70 \%$ ethanol.

\section{Evaluation of the Effect of Crude Extracts on Total WBC Counts in Cyclophosphamide Treated Rats}

Animals were divided into the groups as mentioned in experimental group section. Each group consisted of a minimum of 5 animals. Total WBC were conducted in these groups of rats to establish their total WBC levels. Total 
white blood cell counts in tail blood of rats was determined by the method of Srikumar et al. [13] using a Neubauer haemocytometer. Leukopenia was then induced by treating the rats with $200 \mathrm{mg}$ cyclophosphamide per kilogram body weight intra-peritoneally. Once a drop in the total WBC level was ascertained, treatment with the crude extracts was conducted for a total of three days. The treated groups were dosed orally with the extracts at a dosage of $500 \mathrm{mg} / \mathrm{kg}$ body weight for three consecutive days. The plant crude extracts were administered through intra gastric route using the stomach tube to ensure the safe ingestion of the extracts and the vehicle. Total WBC counts were then conducted to determine if there was reversal of the leukopenic effect of cyclophosphamide. Control groups in all cases received physiological saline.

\section{Results}

Effects of the Extracts of $C$. volkensii and $A$. setaceous on Reversing WBC Reduction in Cyclophosphamide Treated Rats

Four days after CP treatment, there was a significant drop in the mean WBC count to about 6000 cells $/ \mathrm{mm}^{3}$ in all the groups of rats $(\mathrm{P}=0.000)$. A significant increase in mean WBC counts was observed 9 days later after the administration of dichloromethane extract of the $C$. volkensii leaves $(\mathrm{P}=0.002)$. A significant reduction in WBC counts was seen 4 days after $\mathrm{CP}$ treatment $(\mathrm{P}=0.000)$ but following treatment of rats with methanol, ethanol and aqueous extracts of $C$. volkensii leaves, WBC counts was observed to increase significantly 9 days later following administration $(\mathrm{P}=0.000)$. With hexane extract, a significant drop was seen after $\mathrm{CP}$ injection $\left(\mathrm{t}_{4(1)}=21.414, \mathrm{P}=0.000\right)$ whereas the extract was ineffective in reversing the decrease in WBC counts following $\mathrm{CP}$ injection $(\mathrm{P}=0.438)$ (Figure 1).

Four days following $\mathrm{CP}$ treatment, there was a significant drop in the WBC count $(\mathrm{P}=0.000)$. There was no change in WBC counts 9 days later after the administration of dichloromethane extract of the $C$. volkensii stem $(\mathrm{P}=1.000)$. With the methanol, ethanol and aqueous extracts, significant reduction in WBC counts were observed 4 days after $\mathrm{CP}$ treatment $(\mathrm{P}=0.001)$. Methanol, ethanol and aqueous extracts of $C$. volkensii stem caused the WBC counts to significantly rise after 9 days following their administration $(\mathrm{P}=0.001)$. With hexane extract, a significant drop was seen after $\mathrm{CP}$ injection $(\mathrm{P}=0.000)$ whereas the extract was ineffective in reversing the decrease in WBC counts following $\mathrm{CP}$ treatment $(\mathrm{P}=0.885)$ (Figure 2).

WBC count decreased significantly 4 days after $\mathrm{CP}$ treatment $(\mathrm{P}=0.000)$. There was no change in WBC counts 9 days later after the administration of dichloromethane extract of the $C$. volkensii roots $(\mathrm{P}=0.843)$. With the methanol, ethanol and aqueous extracts, significant reduction in $\mathrm{WBC}$ counts were seen 4 days after $\mathrm{CP}$ treatment $(\mathrm{P}=0.000)$. The three extracts caused the WBC counts to significantly rise after 9 days following administering $(\mathrm{P}=0.001)$. With hexane extract, a significant drop was seen after $\mathrm{CP}$ injection $(\mathrm{P}=0.000)$ whereas the extract was ineffective in reversing the decrease in WBC counts following $\mathrm{CP}$ injection $(\mathrm{P}=0.275)$ (Figure 3).

Four days following $\mathrm{CP}$ treatment, there was a significant drop in the WBC count $(\mathrm{P}=0.000)$. There was no alteration in WBC counts 9 days later after the administration of dichloromethane extract of the aerial parts of $A$. setaceous $(\mathrm{P}=0.138)$. With the methanol, ethanol and aqueous extracts, significant reduction in $\mathrm{WBC}$ counts were seen 4 days after $\mathrm{CP}$ treatment $(\mathrm{P}=0.000)$. The three extracts caused the WBC counts to significantly rise after 9 days following their administering $(\mathrm{P}=0.000)$. With hexane extract, a significant drop was seen after $\mathrm{CP}$ injection $(\mathrm{P}=0.000)$ whereas the extract was ineffective in reversing the decrease in WBC counts following $\mathrm{CP}$ injection $(\mathrm{P}=0.636)$ (Figure 4).

After 4 days following $\mathrm{CP}$ treatment there was a significant drop in the WBC count $(\mathrm{P}=0.000)$. There was no change in WBC counts 9 days later after the administration of dichloromethane extract of the roots of $A$. setaceous $(\mathrm{P}=0.398)$. With the methanol, ethanol and aqueous extracts, significant reduction in WBC counts were observed 4 days after $\mathrm{CP}$ treatment $(\mathrm{P}=0.000)$. The three extracts caused the WBC counts to significantly rise after 9 days $(\mathrm{P}=0.000)$. With 
hexane extract, a significant drop was seen after $\mathrm{CP}$ injection $(\mathrm{P}=0.000)$ whereas the extract was ineffective in reversing the decrease in $\mathrm{WBC}$ counts following its injection $(\mathrm{P}=0.069)$ (Figure 5).

$\mathrm{CP}$ treatment was observed to cause a significant drop in the WBC count 4 days after administering $(\mathrm{P}=0.000)$. There was a rise in WBC counts 9 days later after administration of dichloromethane extract of the leaves which was highly significant $(\mathrm{P}=0.002)$. With the dichloromethane extracts of $C$. volkensii stem and root, significant reduction in WBC counts were seen 4 days after $\mathrm{CP}$ treatment $(\mathrm{P}=0.000)$. The two extracts did not have any effect on the WBC counts 9 days after administration $(\mathrm{P}=1.000$ and $\mathrm{P}=0.843)$. With the dichloromethane extract of $A$. setaceous aerial parts, a significant drop was seen after $\mathrm{CP}$ injection $(\mathrm{P}=0.000)$ whereas the extract was ineffective in reversing the decrease in $\mathrm{WBC}$ counts $(\mathrm{P}=0.138)$. The dichloromethane extract of $A$. setaceous root was also ineffective in reversing the decrease in WBC count $(\mathrm{P}=0.398)$ after a significant $\operatorname{drop}(\mathrm{P}=0.000)$ following CP treatment (Figure 6).

A significant drop in the WBC count was observed 4 days after $\mathrm{CP}$ treatment, $(\mathrm{P}=0.000)$. There was a rise in WBC counts 9 days later after the administration of methanol extracts of the $C$. volkensii leaf which was highly significant $(\mathrm{P}=0.000)$. With the methanol extracts of $C$. volkensii stem and root, significant reductions in $\mathrm{WBC}$ counts were seen 4 days after $\mathrm{CP}$ treatment $(\mathrm{P}=0.000)$. The two extracts caused an increase in WBC counts 9 days after administration $(\mathrm{P}=0.001)$. With the methanol extract of $A$. setaceous aerial part, a significant drop was seen after $\mathrm{CP}$ injection $(\mathrm{P}=0.000)$ whereas the extract was very effective in reversing the decrease in WBC counts following $\mathrm{CP}$ injection $(\mathrm{P}=0.000)$. The methanol extract of $A$. setaceous root was also effective in reversing the decrease in WBC count $(\mathrm{P}=0.000)$ after a significant drop $(\mathrm{P}=0.000)$ following $\mathrm{CP}$ treatment (Figure 7).

Four days after $\mathrm{CP}$ treatment, there was a significant drop in the WBC count $(\mathrm{P}=0.000)$. There was a rise in WBC counts 9 days later after the administration of ethanol extracts of the $C$. volkensii leaf which was highly Ogila KO, et al. Int J Pharm Pharmacol significant $(\mathrm{P}=0.000)$. With the ethanol extracts of $C$. volkensii stem and root, significant reduction in $\mathrm{WBC}$ counts were seen 4 days after $\mathrm{CP}$ treatment $(\mathrm{P}=0.001)$. The root extracts caused the WBC counts to rise significantly 9 days after their administration $(\mathrm{P}=0.001)$ while the stem extract did not have an effect $(\mathrm{P}=0.142)$. With the ethanol extract of $A$. setaceous aerial part, a significant drop was seen after $\mathrm{CP}$ injection $(\mathrm{P}=0.000)$ whereas the extract was very effective in reversing the decrease in WBC counts following $\mathrm{CP}$ injection $(\mathrm{P}=0.000)$. The ethanol extract of $A$. setaceous root was also effective in reversing the decrease in WBC count $(\mathrm{P}=0.000)$ after a significant drop $(\mathrm{P}=0.000)$ following $\mathrm{CP}$ treatment (Figure 8).

Four days following $\mathrm{CP}$ treatment, there was a significant drop in the WBC count $(\mathrm{P}=0.000)$. There was no effect on WBC counts 9 days later after administration of hexane extracts of C. volkensii leaf $(\mathrm{P}=0.438)$. With the hexane extracts of $C$. volkensii stem and root, significant reduction in $\mathrm{WBC}$ counts were seen 4 days after $\mathrm{CP}$ treatment $(\mathrm{P}=0.000)$. The two extracts did not cause any rise in the $\mathrm{WBC}$ counts 9 days after administration $(\mathrm{P}=0.885$ and $\mathrm{P}=0.275)$. With the hexane extracts of $A$. setaceous aerial part, a significant drop was seen after $\mathrm{CP}$ injection $(\mathrm{P}=0.000)$ whereas the extract was very ineffective in reversing the decrease in WBC counts following $\mathrm{CP}$ injection $(\mathrm{P}=0.636)$. The hexane extract of $A$. setaceous root was also ineffective in reversing the decrease in WBC count $(\mathrm{P}=0.069)$ after a significant drop $(\mathrm{P}=0.000)$ following $\mathrm{CP}$ treatment (Figure 9).

A significant drop in the WBC count was observed 4 days after $\mathrm{CP}$ treatment, $(\mathrm{P}=0.000)$. There was a rise in WBC counts 9 days later after the administration of aqueous extracts of the $C$. volkensii leaf which was highly significant $(\mathrm{P}=0.000)$. With the aqueous extracts of $C$. volkensii stem and root, significant reductions in WBC counts were seen 4 days after $\mathrm{CP}$ treatment $(\mathrm{P}=0.000)$. The two extracts caused an increase in WBC counts 9 days after administration $(\mathrm{P}=0.001)$. With the aqueous extract of $A$. setaceous aerial part, a significant drop was seen after $\mathrm{CP}$ injection $(\mathrm{P}=0.000)$ whereas the extract was very effective in reversing the decrease in WBC 
counts following $\mathrm{CP}$ injection $(\mathrm{P}=0.000)$. The aqueous extract of $A$. setaceous root was also effective in reversing the decrease in WBC count $(\mathrm{P}=0.000)$ after a significant drop $(\mathrm{P}=0.000)$ following $\mathrm{CP}$ treatment (Figure 10).

\section{Assessing the Time Taken by Methanolic, Ethanolic and Aqueous Extracts of $C$. volkensii and $A$. setaceous in reversing the Effects of Cyclophosphamide}

WBC count was done before any treatment, then on the fourth day after CP treatment. WBC counts were again performed starting on the $3^{\text {rd }}$ day, and then on the $6^{\text {th }}, 9^{\text {th }}, 12^{\text {th }}$ and $15^{\text {th }}$ day after extracts treatment. One group was injected with lithium carbonate and acted as positive control. CP injection caused the WBC counts to drop to 6000 cells $/ \mathrm{mm}^{3}$ in all groups of experimental animals and this was found to be statistically significant (ANOVA, $\mathrm{F}_{6,42}=6.4594$, $\mathrm{P}=0.0001)$. It was observed that the methanolic extracts of $C$. volkensii and $A$. setaceous were effective in reversing a decline in WBC counts induced by $\mathrm{CP}$ injection. Most of the extracts had reversed the negative effect of CP drugs by day 9 which was also found to be statistically significant (ANOVA, $\mathrm{F}_{6,42}=5.7807, \mathrm{P}=0.0002$ ). Lithium carbonate took a few days in reversing the suppressive effect of $\mathrm{CP}$. The control group injected with $\mathrm{CP}$ only experienced decline in WBC counts with levels going below 2500 cells $/ \mathrm{mm}^{3}$ by day 12 (Figure 11).

$\mathrm{CP}$ injection in groups of rats resulted in a significant drop in WBC counts to about 6000 cells $/ \mathrm{mm}^{3}$ after 4 days and this reduction was observed to be statistically significant (ANOVA, $\quad \mathrm{F}_{6,42}=6.86105, \quad \mathrm{P}=0.0000$ ). The ethanolic extracts of the two plants and lithium carbonate were very effective in reversing the decline in WBC counts following CP injection. Lithium carbonate took few days in reversing the suppressive effect of $\mathrm{CP}$ whereas most of the extracts had reversed the negative effect of $\mathrm{CP}$ drugs by day 9 which was also found to be statistically significant (ANOVA, $\mathrm{F}_{6,42}=6.40513, \mathrm{P}=0.0001$ ). There was a rapid decline in WBC counts of the negative control group of rats which never recovered from $\mathrm{CP}$ treatments with their WBC counts going below $2500 \mathrm{~mm}^{3}$ by day 12 (Figure 12).
A drop in WBC counts was seen following $\mathrm{CP}$ injection (ANOVA, $\quad \mathrm{F}_{6,42(1)}=5.772427$, $\mathrm{P}=0.0002$ ). From Figure 13, it can be seen that the aqueous extracts and lithium carbonate were very effective in reversing a decline in WBC counts and lithium carbonate took a few days in reversing the suppressive effect of CP whereas most of the extracts had reversed the negative effect of CP drugs by day 9 which was also found to be statistically significant (ANOVA, $\left.\quad \mathrm{F}_{6,42(1)}=7.080849, \quad \mathrm{P}=0.000049\right)$. There was a rapid decline in the negative control group with WBC counts levels going below $2500 \mathrm{~mm}^{3}$ by day 13 .

The extracts of aqueous, ethanol and methanol of $C$. volkensii leaves, stem and roots and A. setaceous aerial parts and roots were also evaluated on their ability to protect pretreated rats against cyclophosphamide induced myelosuppression and to determine whether pretreatment is necessary. The methanolic extracts of $C$. volkensii and A. setaceous caused a rise in WBC counts by day 9 following their administration. Cyclophosphamide treatment caused a drop in the WBC counts three days later in all groups of experimental animals which then remained almost at the same level at day 6, 9 and 12. When compared to the negative control, the extracts performed well in protecting the rats from the effects of $\mathrm{CP}$. Lithium carbonate proved to be superior to all the extracts (Figure 14).

All the ethanolic extracts caused an increase in WBC counts by day 9 (Figure 15). Cyclophosphamide treatment caused a drop in the WBC counts 3 days after its administration. For most ethanolic extracts WBC counts then stabilized by day 6 and remained at the same level at day 9 and 12 . WBC counts decreased to very low levels in the negative control group with the count dropping to about 3000 cells $/ \mathrm{mm}^{3}$.

All the aqueous extracts caused a rise in WBC counts by day 9 . Cyclophosphamide treatment caused a drop in the WBC counts 3 days after its injection and this continued to drop slightly but had stabilizes by day 6 and then remained stable at day 9 and 12 . WBC count at day 12 after cyclophosphamide injection was almost at the same level of WBC counts at the beginning of the experiments before the rats were treated 
with any extracts. This was an indication that the aqueous extracts could actively protect the rats from the suppressive effects of $\mathrm{CP}$ (Figure 16).

\section{Discussion}

As expected, cyclophosphamide caused a significant drop in WBC in rats, but upon treatment of the rats with the methanol, ethanol and aqueous extracts of $C$. volkensii (leaf, stem and root) and A. setaceous (aerial part and root), an increase in total WBC was observed, when compared to the negative control treated with cyclophosphamide. Lithium carbonate was superior to extracts in reversing the effects of cyclophosphamide induced leukopenia. In pretreated rats, methanol, ethanol and aqueous extracts of $C$. volkensii (leaf, stem and root) and A. setaceous (aerial part and root), were found to have an active protective effect in rats, when administered before cytostatic. Injection of a single dose of $200 \mathrm{mg} / \mathrm{kg}$ cyclophosphamide produced a fall in total WBC on the third day. A rebound increase in total WBC count occurred on the $9^{\text {th }}$ day. The leukopenia which occurred in control animals following cyclophosphamide was less marked in the treated animals. A point to note is that WBC counts in all extract treated animals never went below $6000-8000$ cells $/ \mathrm{mm}$ after injection of cyclophosphamide. Thatte et al. [14] reported that $A$. racemosus could be producing leucocytosis probably by activating macrophages. Activated macrophages are known to secrete a large number of colony stimulating factors and IL-1 which in turn stimulate other immunocytes like neutrophils [4]. IL-1 and CSF are substances known to cause leucocytosis and it appeared that activation of macrophage produced protection of the rats against cyclophosphamide induced leukopenia. It may be that the extracts of $A$. setaceous and $C$. volkensii also act in this manner to confer protection. The methanolic, ethanolic and aqueous extracts showed an increase in WBC. These results are also in agreement with other studies. Administration of the ethanolic extract of $A$. paniculata in cyclophosphamide treated mice was found to enhance total WBC count which was drastically reduced in the cyclophosphamide alone treated control animals suggesting that cyclophosphamide induced myelosuppression was reversed or inhibited by extract administration through its immunomodulating activity [6]. Preclinical studies investigating the effect of $A$. racemosus against the myelosuppressive effects of single and multiple doses in mice showed that it prevented to a significant degree, leukopenia produced by cyclophosphamide. It is now accepted that $A$. racemosus is a potent immune-stimulant with effects comparable to lithium and glucan producing leucocytosis with predominant neutrophilia [14]. Nayak and Abhilash [5] demonstrated that alcoholic extract of Pimenta dioica leaves increased WBC counts in mice treated with cyclophosphamide after 10 days of treatment. The increase in WBC was attributed to the immune stimulant properties of the $P$. dioica. In another study whose result conflicts with the result of this study, Khoo and Ang [7] demonstrated that the aqueous extracts of Astragalus membraneceus and Ligustrum did not prevent cyclophosphamide induced myelosuppression. It did not delay the onset, hasten the recovery or shorten the duration of Leukopenia. Geidam et al. [15] demonstrated that aqueous stem extract of Momordica balsamina linn elevated WBC counts in normal rats but did not affect other hematological parameters. Administration of Rubia cordifolia was demonstrated to increase total WBC count in immunocompromised albino rats indicating that the extract was able to stimulate hemotopoetic system. n- butanol soluble and ethyl acetate soluble fractions of methanolic extract of Lagenaria siceraria fruits significantly increased the WBC and lymphocyte counts. Increase in WBC count was observed in Withania somnifera treated mice compared to untreated control [16]. In a review by Sagrawat and Khan [17], A. racemosus was reported to protect rat and mice against experimentally induced abdominal sepsis while oral administration of decotion of powdered roots of $A$. racemosus produced leucocytosis along with enhanced phagocytic activity of the macrophages and polymorphs. Sheeja and Kuttan [6] demonstrated that intraperitoneal administration of the extracts of Andrographis paniculata significantly increased the total WBC count and bone marrow cellularity.

\section{Conclusion}


The study has demonstrated that aqueous, ethanolic and methanolic extracts of $A$. setaceous and $C$. volkensii are effective in protecting rats against cyclophosphamide induced leukopenia. It showed that the extracts offer protection against cyclophosphamide induced myelosuppression and hence holds promise as candidates to overcome this problem. These results open up exciting possibilities for the use of plant products in the prevention of adverse bone marrow effects associated with cyclophosphamide treatment.

\section{References}

1. Bao YX, Wong CK, Leung SF, et al. Clinical studies of Immunomodulatory activities of Yunzhi Danshen in patients with Napopharyngeal carcinoma. J Altern Complimentary Med 2006; 12: 771-776.

2. Thatte UM, Chhabria SN, Karandikar SM, et al. Protective effects of Indian medical plants against cyclophosphamide neutropenia. J Postgrad Med 1978; 33: 185-188.

3. Morris HJ, Llaurado MJ, Fontaine $\mathrm{G}$, et al. (2003) Immunomodulating effects of hotwater extract from Pleurotus Ostreatus mycelium on cyclophosphamide treated mice. Micol Aplicada Int 2003; 15: 713.

4. Joshi UP, Mishra SH. (2008) Evaluation of aqueous and methanol extracts of Pistacia integerrima galls as potential immunomodulator. Pharmacogn Mag 2008; 4: 126-131.

5. Nayak Y, Abhilash D. Protection of cyclophosphamide induced myelosuppression by alcoholic extract of Pimenta dioica leaves in mice. Pharmacologyonline 2008; 3: 719-723.

6. Sheeja K, Kuttan G. Ameliorating effects of Andrographis paniculata extract against cyclophosphamide induced toxicity in mice. Asian Pac J Cancer Prev 2006; 7: 609-614.

7. Khoo KS, Ang PT. Extract of Astragalus membranaceus and Ligustrum lucidum does not prevent cyclophosphamide induced myelosuppression. Singapore Med J 1995; 36: 387-390.

8. Iwu MM. Handbook of African medicinal plants. 2000; CRC Press Inc, USA.

9. Kokwaro O. Medicinal plants of East Africa. 2000; East African Literature, Nairobi.

10. Ogila KO., Ng'ang'a Z, Shililu J, et al. Stimulatory effects of Asparagus setaceous Kunth on innate and cell mediated immunity in normal albino rats. Int $\mathbf{J}$ Biol Sci 2010; 2: 68-81.

11. Aduol OM, Ogila KO. Enhancement of the nonspecific immune system by extracts of Asparagus africanus Kunth and Caesalpinia volkensii. Asian J Pharma Health Sci 2012; 2: 420-427.

12. Ogila KO, Josephat M, Aduol OM. Stimulatory effects of Caesalpinia volkensii Harmon innate and cell mediated immunity in Balb/c mice. Asian J Pharma Health Sci 2013; 3: 753-762.

13. Srikumar R, Parthasarathy NJ, Devi RS. Immunomodulatory Activity of Triphala on Neutrophil functions. Biol Pharm Bull 2005; 28: 1398-1403.

14. Thatte UM, Dahanukar SA. Comparative study of immunomodulating activity of Indian medicinal plants, lithium carbonate and glucan. Methods Find Exp Clin Pharmacol 1988; 10: 639-644.

15. Geidam MA, Pakman I, Laminu H. Effects of aqueous stem bark extract of Momordica balsamina Linn on serum electrolytes and some hematological parameters in normal and alcohol fed rats. Pak J Biol Sci 2004; 7: 1430-1432.

16. Mishra LC, Singh BB, Dagenais S. Scientific basis for the therapeutic use of Withania somnifera (Ashwagandha): A review. Altern Med Rev 2005; 5: 334-346.

17. Sagrawat H, Khan MY. Immunomodulatory plants: A phytopharmacological review. Pharmacogn Rev 2007; 1: 248-260. 


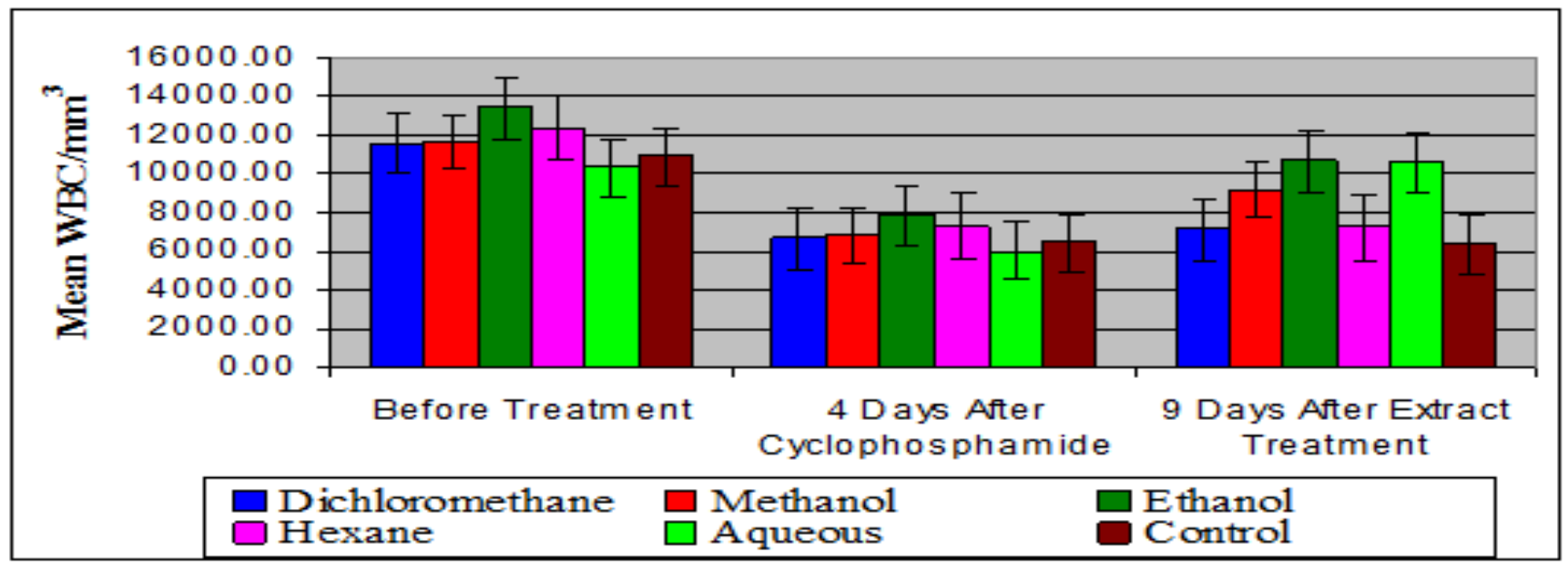

Figure 1: Effect of dichloromethane, methanol, ethanol, hexane and aqueous extracts of $C$. volkensii leaves on WBCs counts in rats 4 days after cyclophosphamide treatment and 9 days later after extracts treatment.

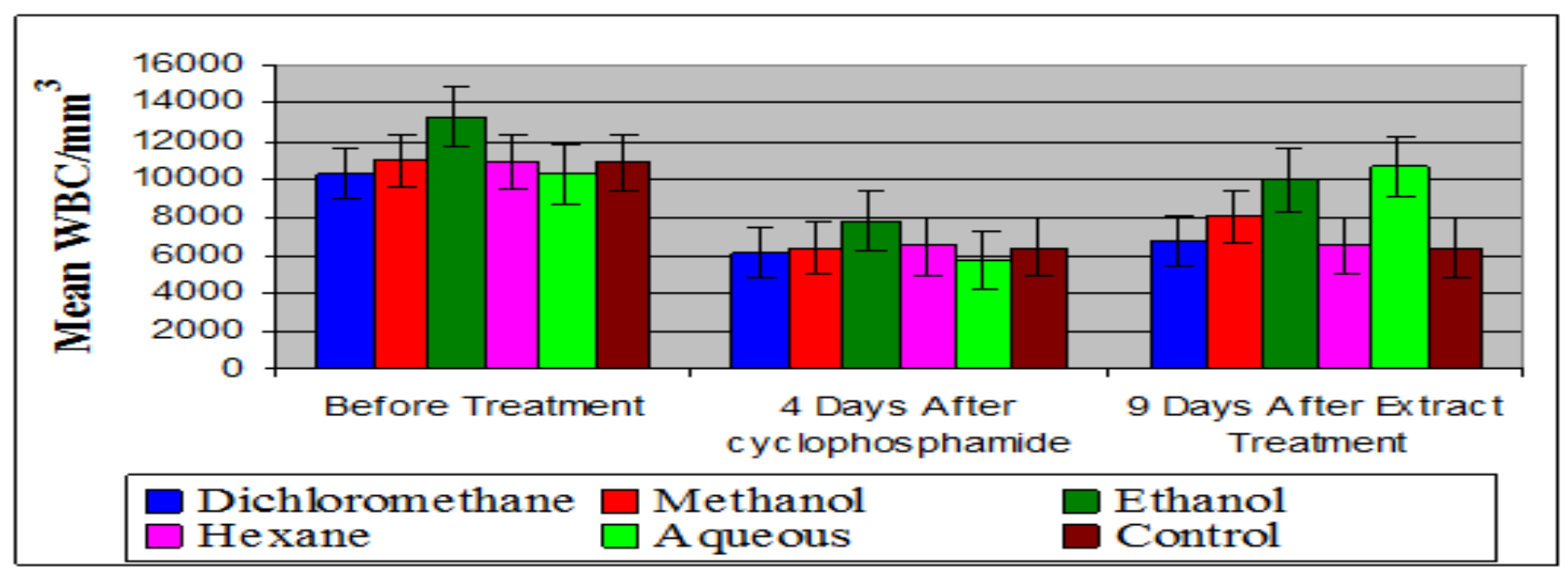

Figure 2: Effect of dichloromethane, methanol, ethanol, hexane and aqueous extracts of $C$. volkensii stem on WBCs counts in rats treated with cyclophosphamide.

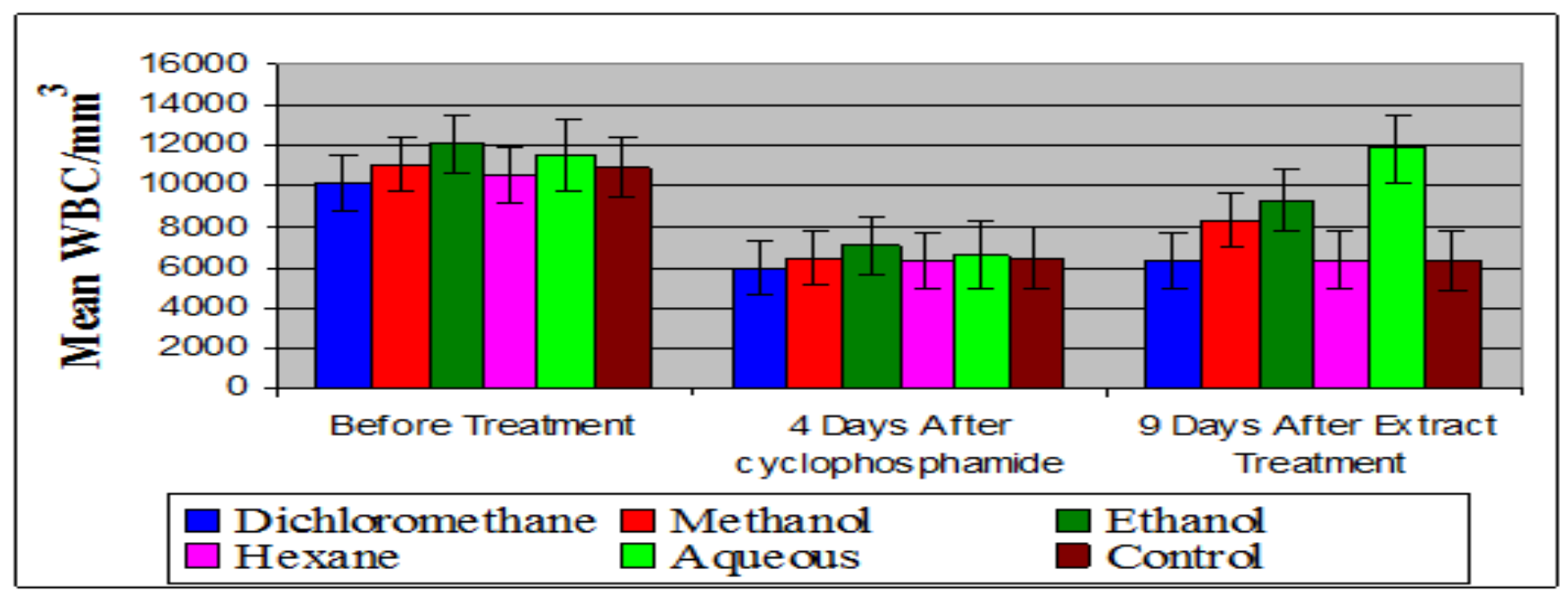

Figure 3: Effect of dichloromethane methanol, ethanol and hexane extracts of $C$. volkensii root on WBCs counts in rats treated with cyclophosphamide. *Control group was administered with dimethyl sulfoxide. 


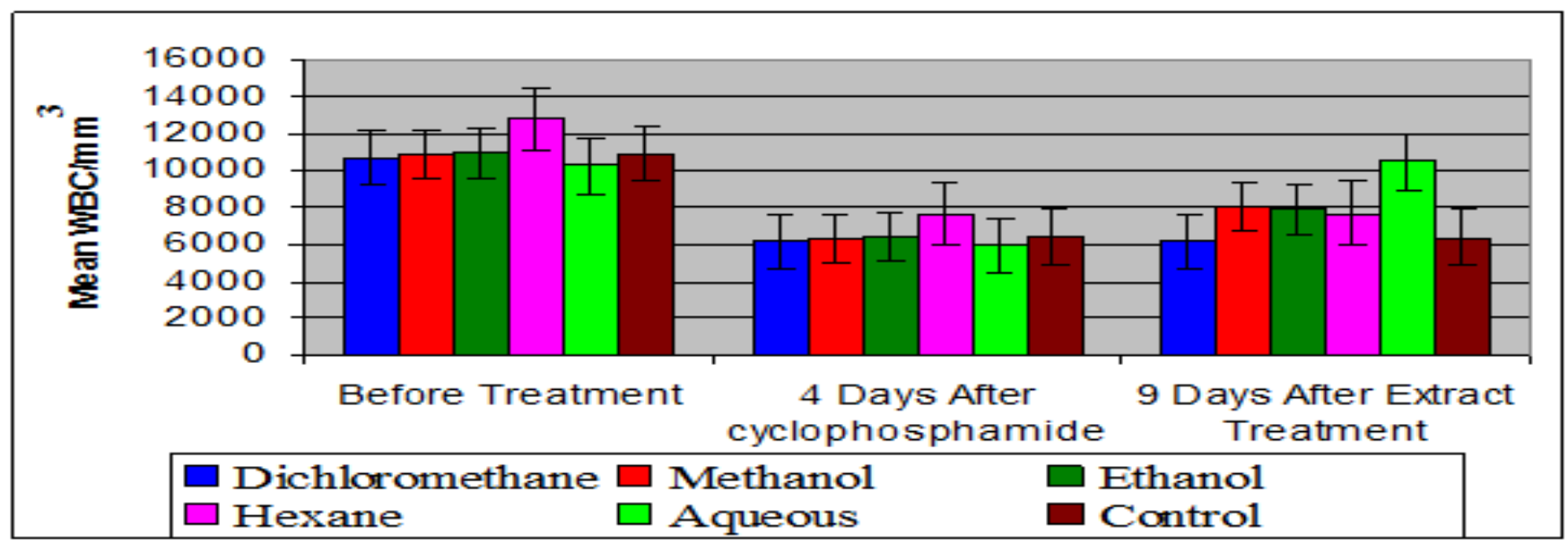

Figure 4: Effect of dichloromethane, methanol, ethanol, hexane and aqueous extracts of $A$. setaceous aerial part on WBCs counts in rats treated with cyclophosphamide. *Control group was administered with dimethyl sulfoxide.

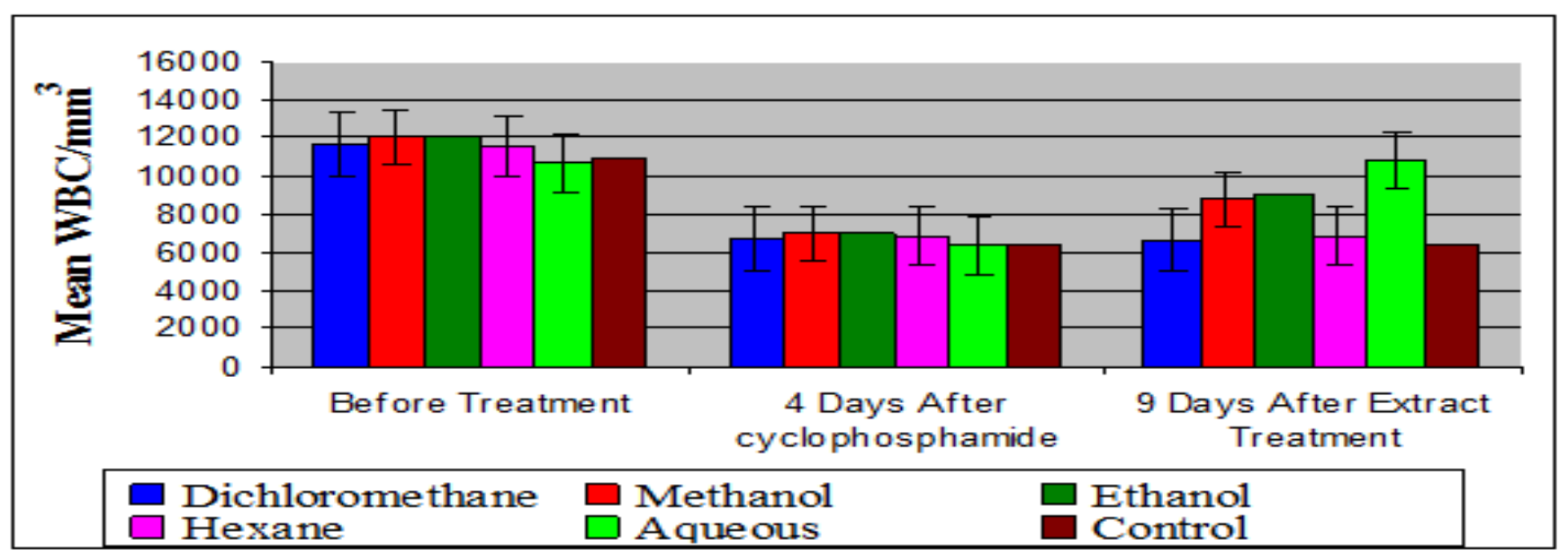

Figure 5: Effect of dichloromethane methanol, ethanol hexane and aqueous extracts of $\boldsymbol{A}$. setaceous roots on WBCs counts in rats treated with cyclophosphamide. *Control group was administered with dimethyl sulfoxide.

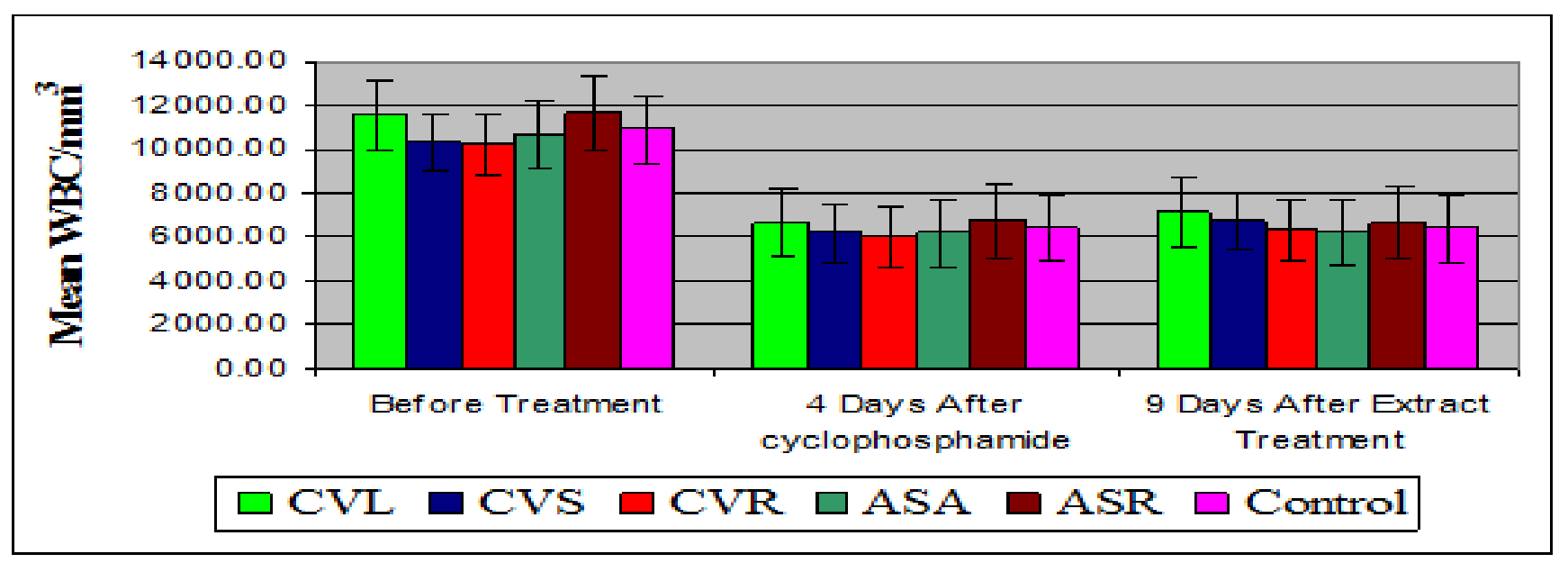

Figure 6: Effects of dichloromethane extracts of $C$. volkensii and $A$. setaceous on WBC counts in rats treated with cyclophosphamide*Control group was administered with dimethyl sulfoxide. 


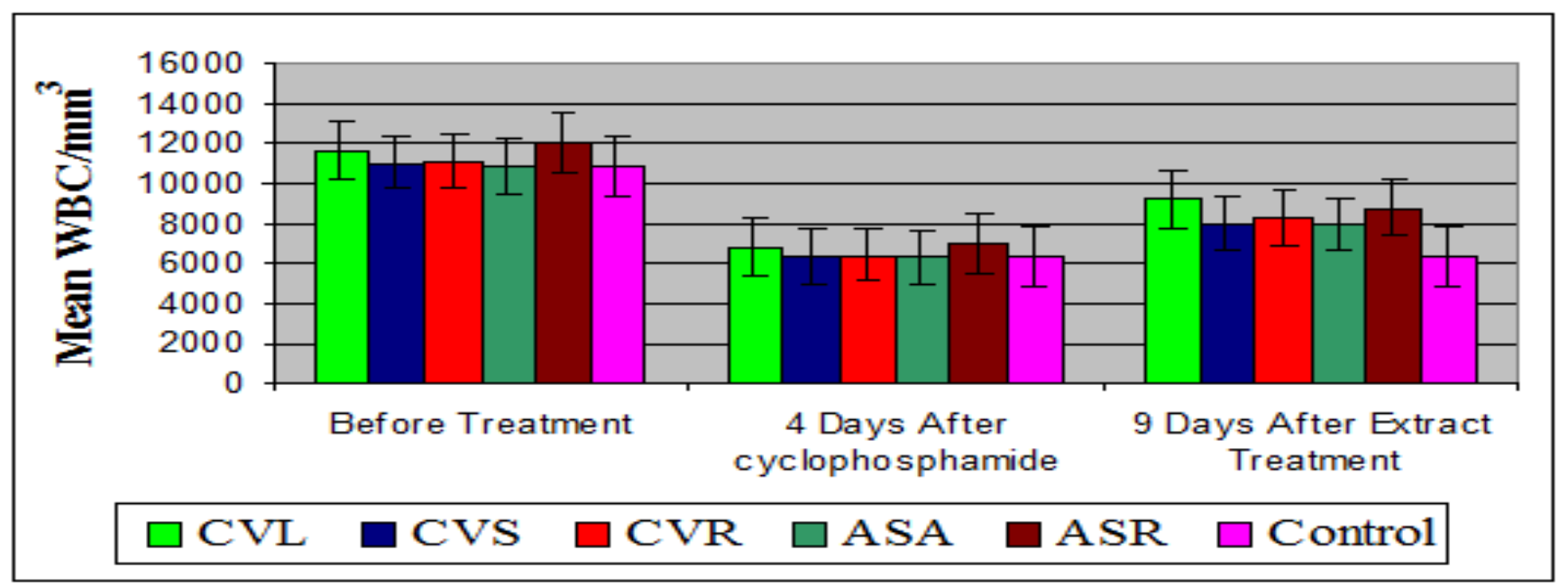

Figure 7: Effects of methanol extracts of $C$. volkensii and A. setaceous on WBCs counts in rats treated with cyclophosphamide.

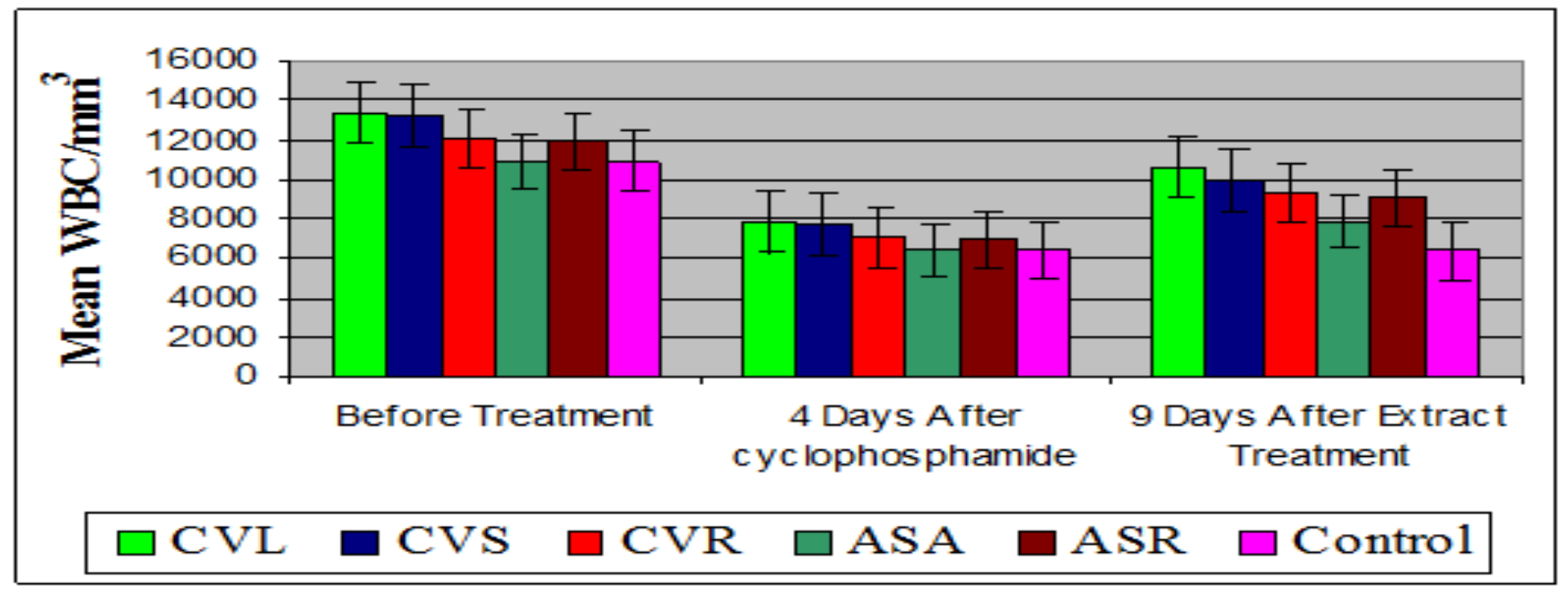

Figure 8: Effects of ethanol extracts of $C$. volkensii and A. setaceous on WBCs counts in rats treated with cyclophosphamide.

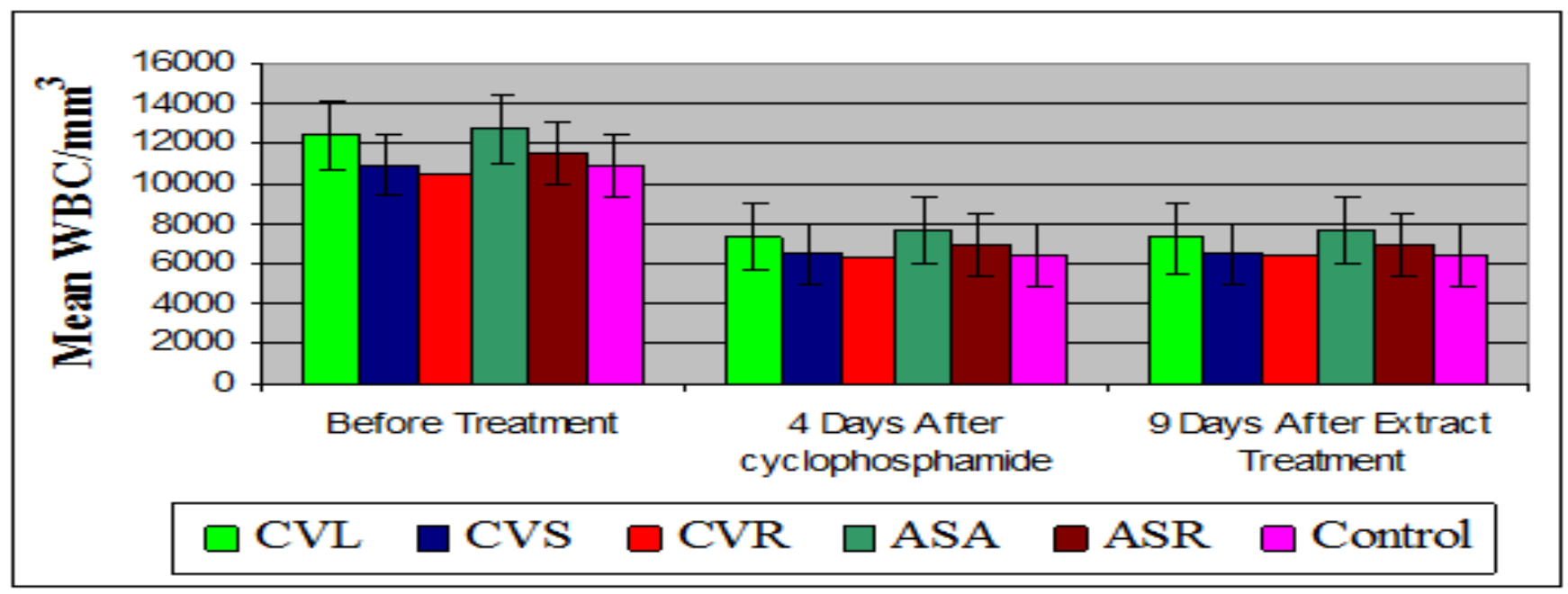

Figure 9: Effects of hexane extracts of $C$. volkensii and A. setaceous on WBC counts in rats treated with cyclophosphamide. 


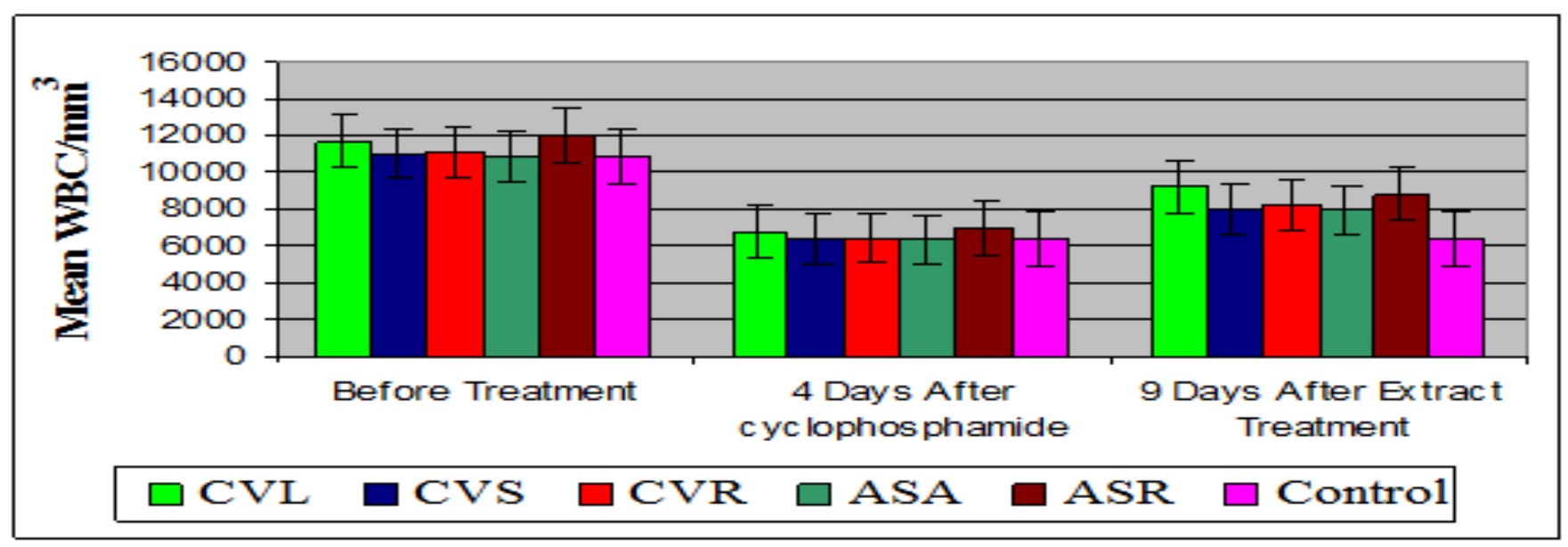

Figure 10: Effects of Aqueous extracts of $C$. volkensii and A. setaceous on WBCs counts in rats treated with cyclophosphamide. *Control group was administered with dimethyl sulfoxide.

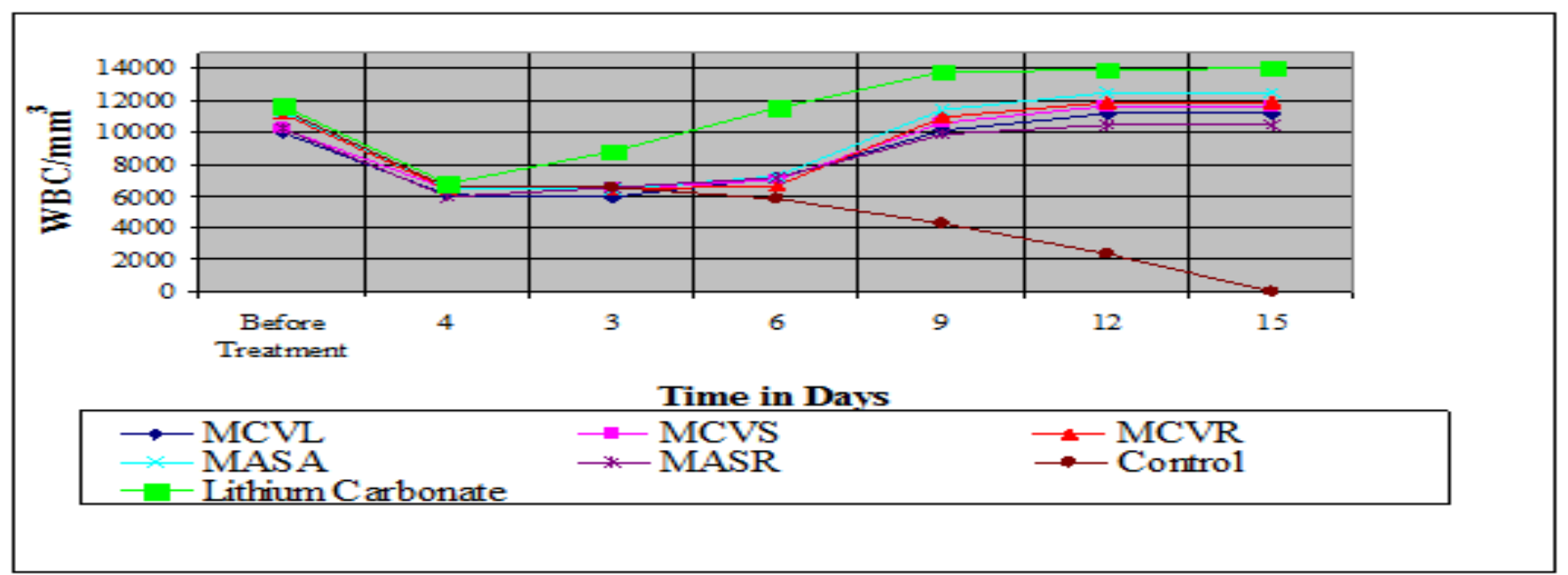

Figure 11: Effects of methanol extracts of A. setaceous and C. volkensii on cyclophosphamide treated rats. *Control group was administered with dimethyl sulfoxide while group administered lithium carbonate acted as positive control.

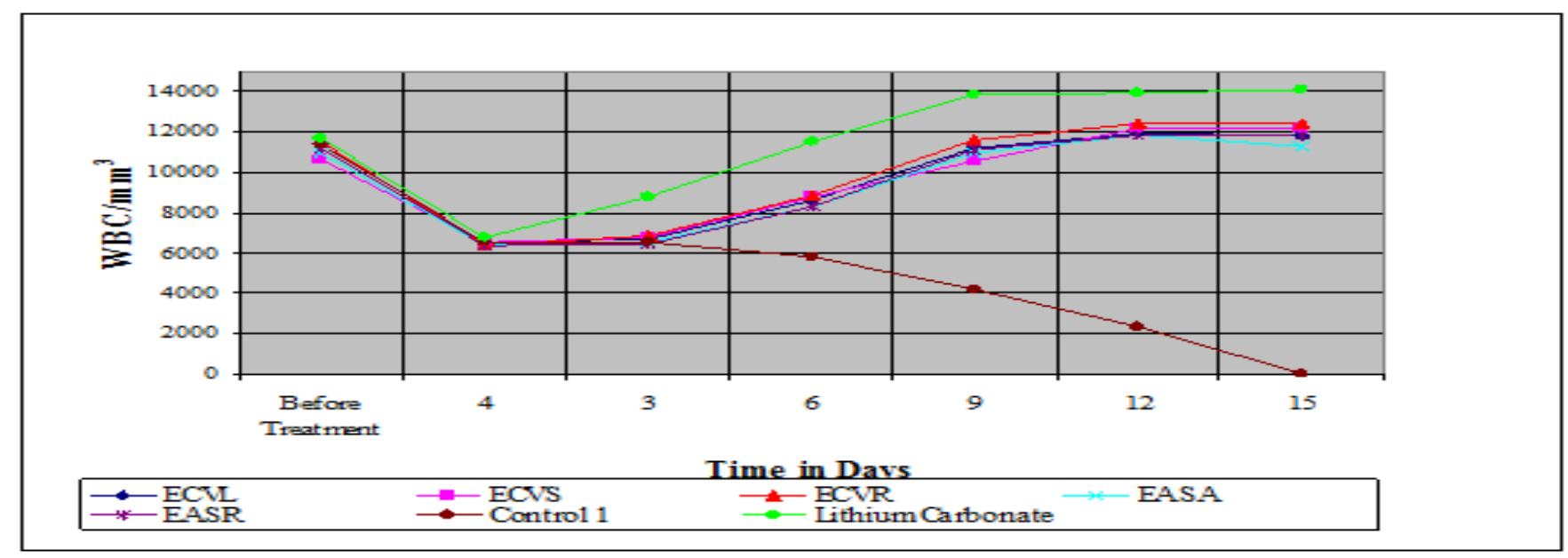

Figure 12: Effects of ethanol extracts of $A$. setaceous and $C$. volkensii in cyclophosphamide treated rats. *Control 1 group was administered with dimethyl sulfoxide while group administered lithium carbonate acted as positive control. 


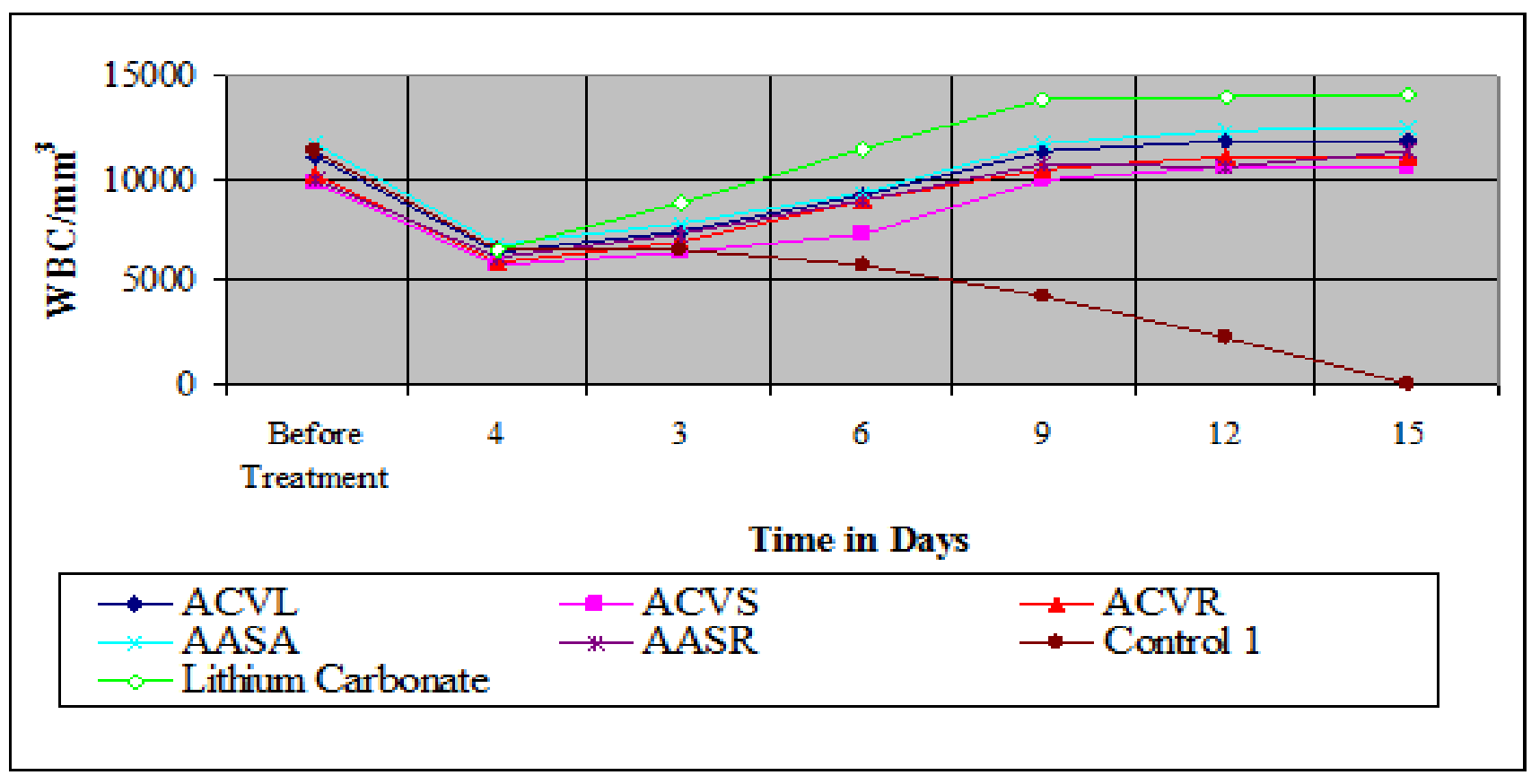

Figure 13: Effects of aqueous extracts of $A$. setaceous and $C$. volkensii in cyclophosphamide treated rats.

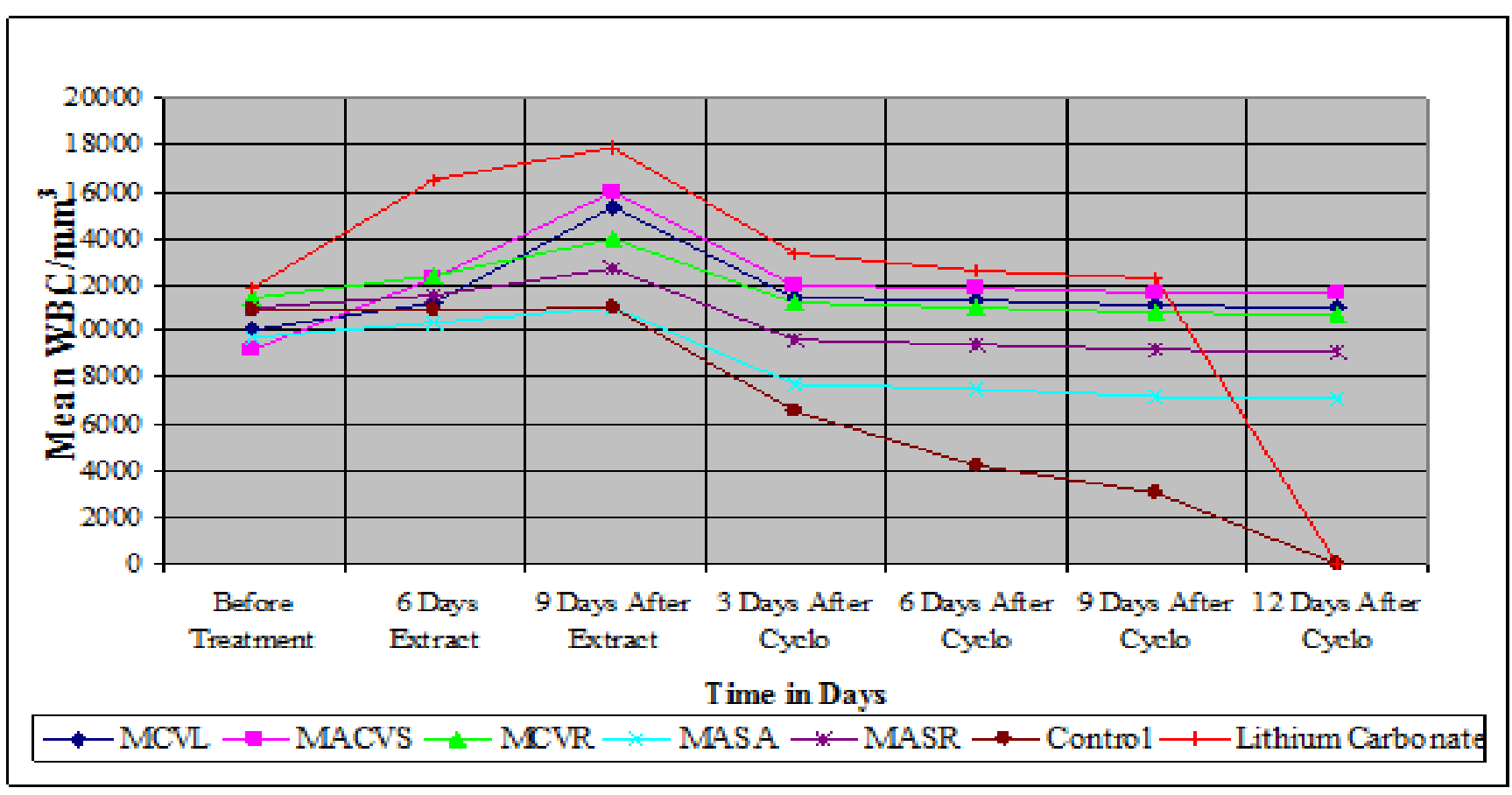

Figure 14: The effect of methanolic extracts of $C$. volkensii and A. setaceous against myelosuppression induced by cyclophosphamide in pre-treated rats. *Control group was administered with dimethyl sulfoxide while group administered lithium carbonate acted as positive control. 


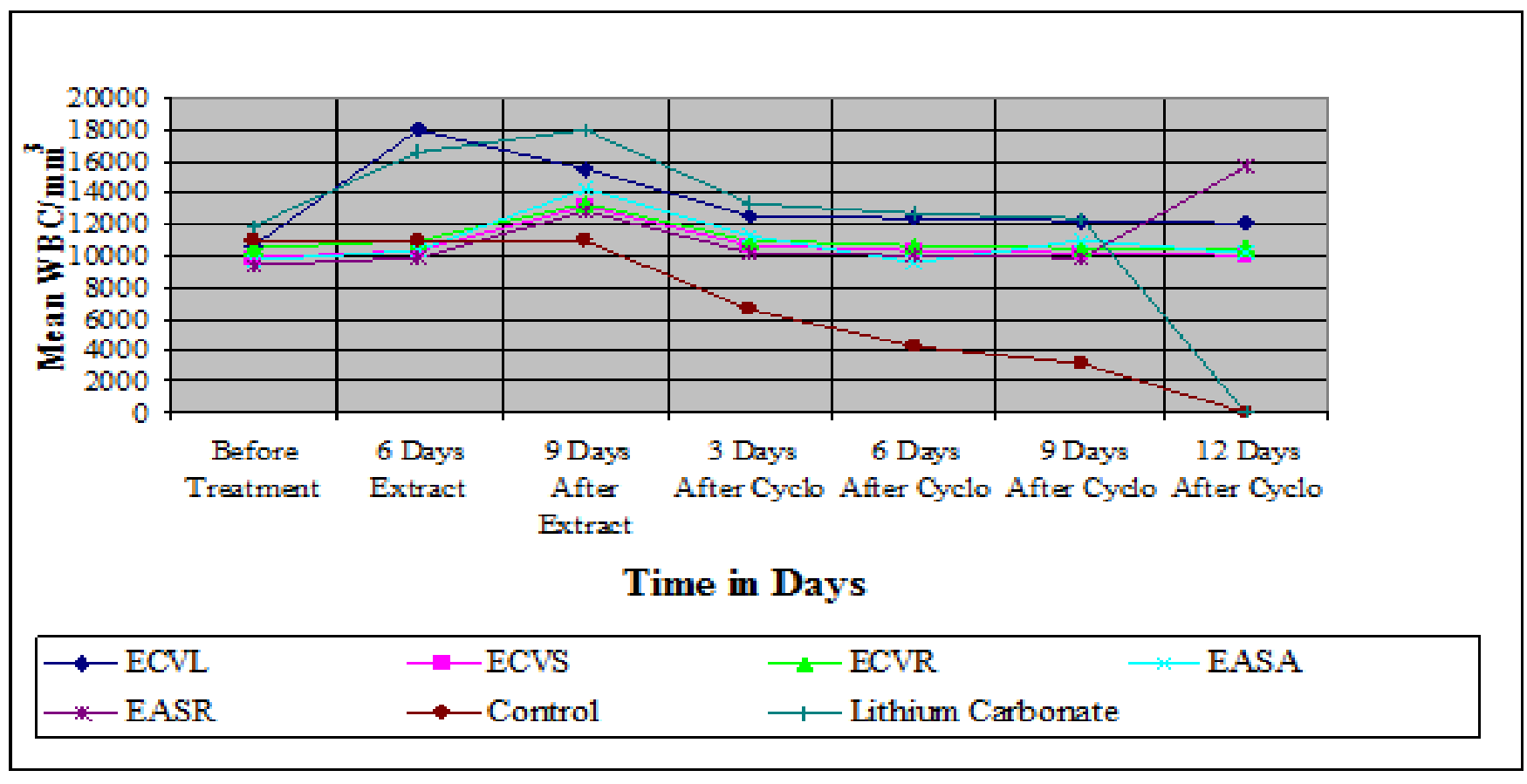

Figure 15: The effect of ethanolic extracts of $C$. volkensii and $A$. setaceous against myelosuppression induced by cyclophosphamide in pre-treated rats. *Control group was administered with dimethyl sulfoxide while group administered lithium carbonate acted as positive control.

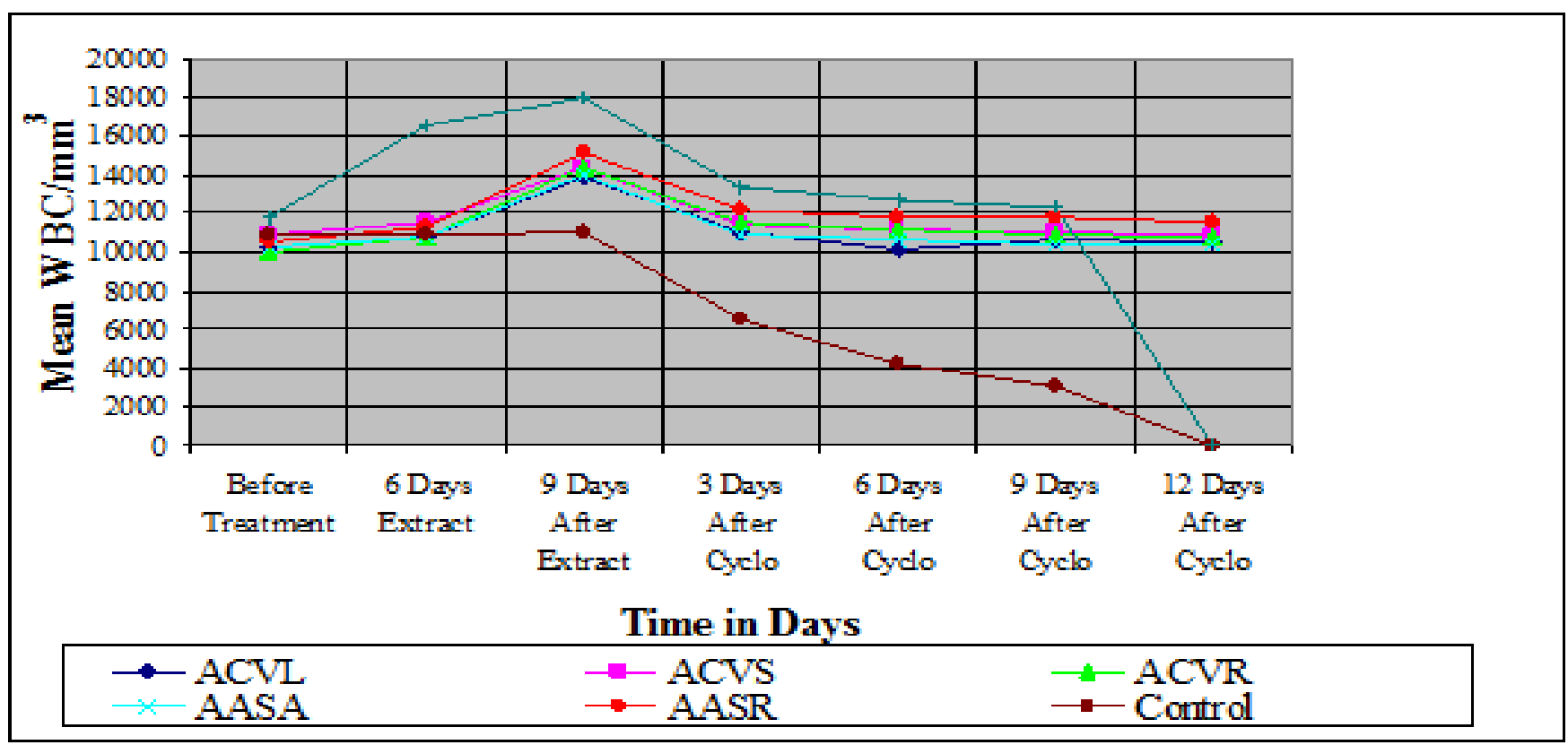

Figure 16: The effect of aqueous extracts of $C$. volkensii and $A$. setaceous against myelosuppression induced by cyclophosphamide in pre-treated rats. *Control group was administered with dimethyl sulfoxide while group administered lithium carbonate acted as positive control. 
This manuscript was peer-reviewed

Mode of Review: Single-blinded

\section{Editor: Dr. Imran Kazmi}

International Journal of Pharmaceutics and Pharmacology is an open access, peer reviewed journal published by Edwiser International.

Submit your valuable manuscript at-

editor.ijpp@edwiserinternational.com

submit.manuscript@edwiserinternational.com

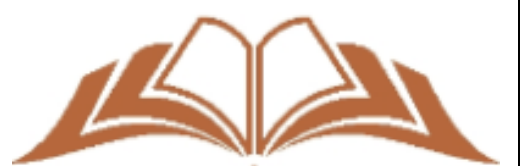

$\mathrm{E} D \mathrm{~W}(\hat{\theta} \mathrm{SER}$
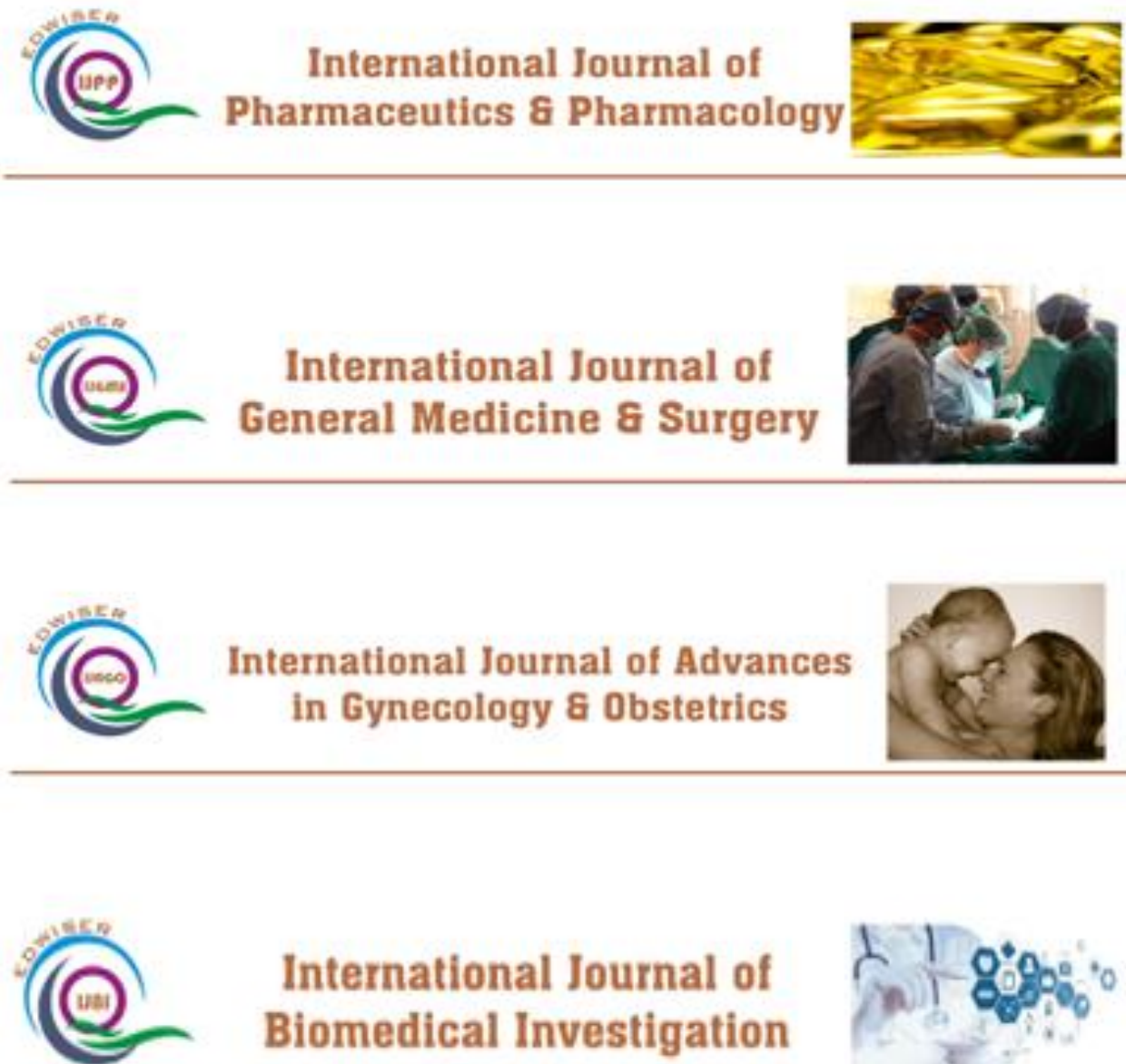

\section{International Journal of Biomedical Investigation}
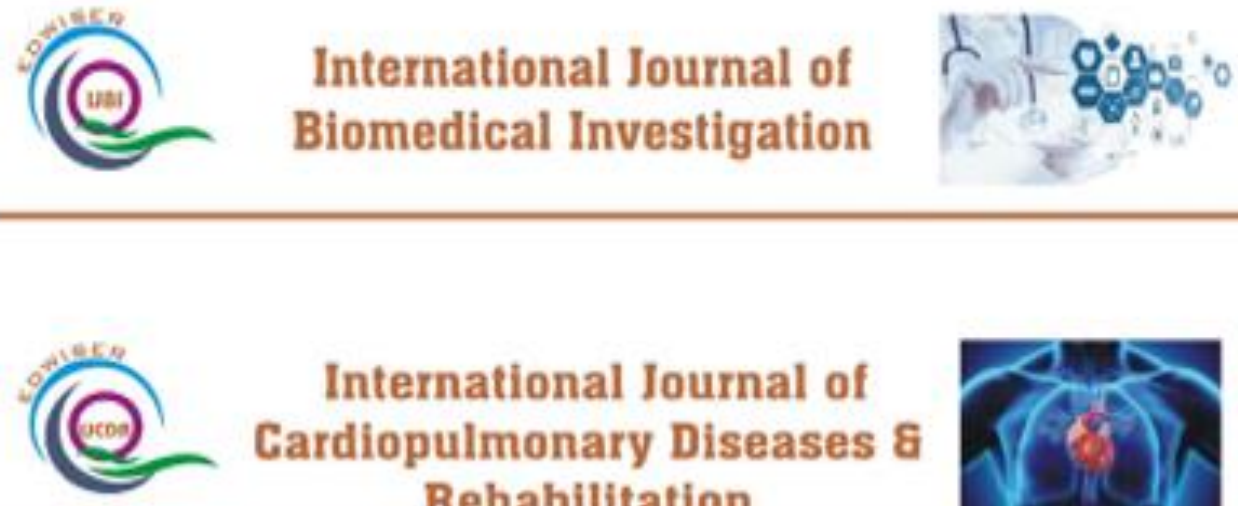

International Journal of Cardiopulmonary Diseases \& Rehabilitation

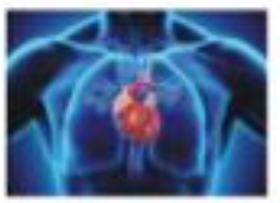

